\title{
Designing Lightweight Structures under Consideration of Material and Structure Uncertainties on Different Levels of the Building Block Approach
}

\author{
Tobias S. Hartwich ${ }^{1 *}$, Harald Völkl ${ }^{2}$, Sandro Wartzack ${ }^{2}$, Dieter Krause ${ }^{1}$ \\ ${ }^{1}$ Institute of Product Development and Mechanical Engineering Design, Hamburg University of Technology \\ ${ }^{2}$ Engineering Design, Friedrich-Alexander-Universität Erlangen-Nürnberg \\ * Corresponding Author: \\ Tobias S. Hartwich \\ Denickestraße 17 \\ D-21073 Hamburg, Germany \\ Phone: +49 (0)40 428784466 \\ Mail: tobias.hartwich@tuhh.de
}

\begin{abstract}
Lightweight design is an important aspect in the development of components to reduce material use and obtain energy-efficient structures. Frequently, lightweight structures are designed for one or a few load cases. Therefore, optimized designs can be less robust against changes in boundary conditions, scattering material parameters or deviating tolerances. Thus, these structures must be designed with safety factors that counteract the targeted lightweight design goal. In this article, an approach for the consideration of uncertainties is presented. The approach allows evaluating potentials of the accurate consideration of uncertainties. Finally, the developed approach is implemented for the calculation of the buckling load and torsional strength of thin-walled CFRP cylinderical shells.
\end{abstract}

\section{Keywords}

CFRP, Uncertainties, Lightweight Design, Buckling, Building Block Approach 


\section{Motivation}

Lightweight design is an important aspect in the development of components, e.g. in the aerospace industry, to reduce material use and obtain energy-efficient structures [1]. Frequently, lightweight structures are designed just for one or a few load cases. When optimized for these load cases, designs can be less robust against changes in boundary conditions, scattering material parameters or deviating tolerances [2]. Therefore, these structures must also be designed with safety factors that counteract the targeted lightweight design goal. One way to solve this problem is to take into account the occurring uncertainties, as probabilistic design approaches do [3]. Furthermore, a source of errors in the design are influences of omitted or incorrectly considered boundary conditions [2]. If the boundary conditions are not transferred correctly, errors can occur. If, for example, a component is designed with an FE model and this FE model has been validated in a verification test for which other boundary conditions were present and the change of the boundary conditions are not taken into account in the transfer to the application, a safe design is not given. Rather, this component was only designed for the verification test [2]. Therefore, this paper shows how uncertainties can be treated in order to ensure a reliable design as well as how data between the test and simulations has to be handled.

\section{Design Approaches}

This section describes two approaches to the design and testing of lightweight structures. The Building Block Approach, which is commonly used in aerospace industry, is described at the beginning. In the second half, the advantages and challenges of probabilistic design approaches are discussed.

\subsection{Building block approach}

A common practice in the aerospace industry for the development of components is the Building Block Approach [4]. The Building Block Approach proposes a hierarchical method. It is comparable to a multiscale analysis. On the lower blocks or levels of the test pyramid illustrated in Figure 1 (a) are tests, and simulations on the material level.

(a)

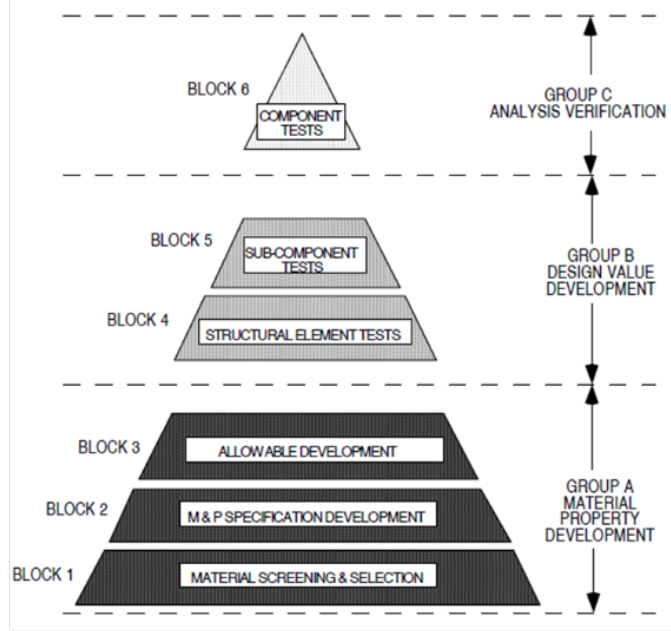

(b)

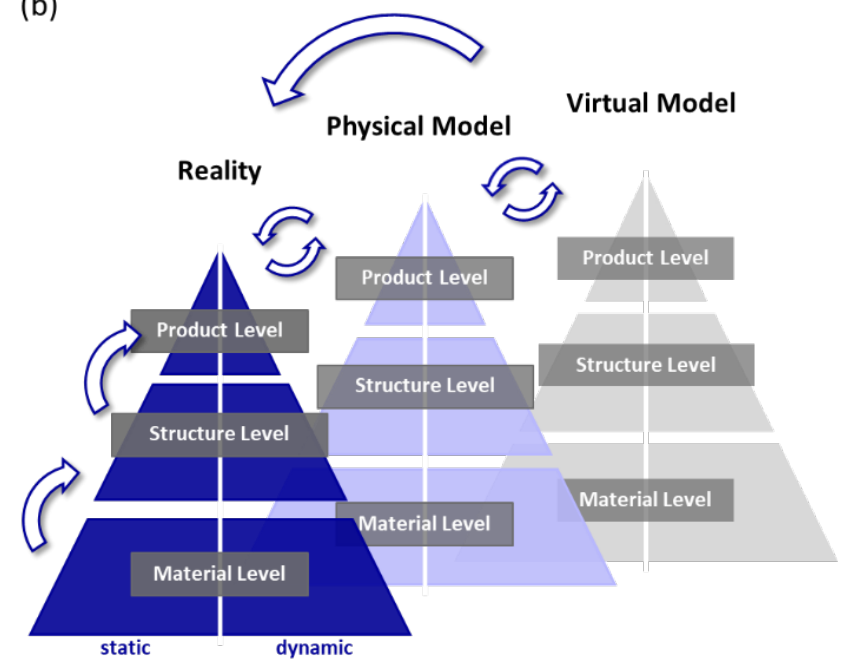

Figure 1: Building Block Approach according to [4] (a) and extended Building Block Approach according to [2] (b) 
A comparatively large number of tests are performed at these levels. Then the results are transferred to the next level and new analyses on a more complex structure have to be conducted. With each step up to a higher level, the element under consideration becomes more similar to the component and the number of tests is reduced. At the top of the test pyramid is the the complete component or the product, which is only tested in one verification test.

Heyden et. al. extended in [2] the building block approach by a third dimension, so-called layers, to deal with the problems of transferability between simulation, testing and application. For simplification, the test pyramid consists only of three levels: The material level, the structure level and the product level; however, it differentiates between static and dynamic problems. The main point of this approach is that during a transfer, either one level within a pyramid can be moved up or the layer can be changed. For each transfer, the designer must be aware of the constraints and assumptions under which the results of the previous step were achieved and how they may influence further results.

\subsection{Deterministic and probabilistic design}

For the robust design of components, the occurring material, structural and load uncertainties must be taken into account. Several options are available for this. Classically, these are considered in deterministic designs by global safety factors. If the scatters are not known exactly, correspondingly large safety factors must be selected, which may lead to very conservative designs and counteract a desired lightweight design goal. An extension for a more accurate design is the use of partial safety factors (semi-probabilistic methods), as proposed in the Eurocodes, for example, in civil engineering [5], [6].

The next design step is the consideration of the distributions of occurring uncertainties in the design. One possibility for this is the Monte Carlo method, which provides a discrete approximation of the probability distribution of the design quantity, i.e. the target quantity, based on randomly generated realizations. However, for a robust design (high accuracy and low error probability), a large number of realizations are required, so that Monte Carlo methods are extremely costly. One possibility for reducing the computational effort is offered by the socalled probabilistic approximations, such as the first-order reliability methods [3]. In order to carry out a reliability-based design, it is necessary to determine the relevant influencing parameters and their distribution. A common problem is that the value and distribution of many of the influencing parameters are not known and therefore have to be determined or assumed in a complex way [7].

\section{Research problem and objective}

Therefore, the question is raised how and to what extent material and structural uncertainties have to be considered in the design of lightweight structures. In this article an approach for the consideration of uncertainties is presented. Furthermore, a comparison to classical design is shown. Hence, the approach allows evaluating potentials of the accurate consideration of uncertainties. Finally, the developed approach is implemented for the calculation of the buckling load and torsional strength of thin-walled Carbon Fiber Reinforced Plastic (CFRP) cylinderical shells. The present example of thin-walled CFRP cylinderical shells is chosen because these structures are highly sensitive to deviations under compressive load. 


\section{Proposed Approach}

Based on [2] the building approach is extended with consideration of uncertainieties. The uncertainties include for instance distribution of material parameters on the material level, form deviations or varying load conditions. These occurring uncertainties are considered in each step, e.g. from the material to the structure level, and are taken into account in each transfer between the virtual and physical model and reality. Influencing parameters and their distributions have to be quantified in experiments. Probabilistic methods such as Monte Carlo simulations [3] can be used in the virtual model in order to consider these uncertainities. Thus, a robust design can be enabled and the safety factor can be reduced.

\section{Application}

In this section the application of the proposed approach is shown. Starting at the material level, material parameters of composite specimens are determined. Then the test results are checked in a virtual model and the missing material parameters are determined by simulation. After that, the results are transferred successively to the structural level. The analysed structure is a thin-walled CFRP cylindrical shell. Such structures are used in rockets as socalled interstages and tend to buckle under compressive load. In addition to the material parameters, the buckling load is significantly influenced by geometry and load deviations [8]. On the structural level, this information from literature values is therefore taken into account. Different levels of detail are used for this purpose. Finally, the results are compared with a test result. In addition, the strength of the cylinder during torque application is considered, since torsional moments can occur during assembly in the test setup. In Figure 2 the application of the proposed approach is shown.

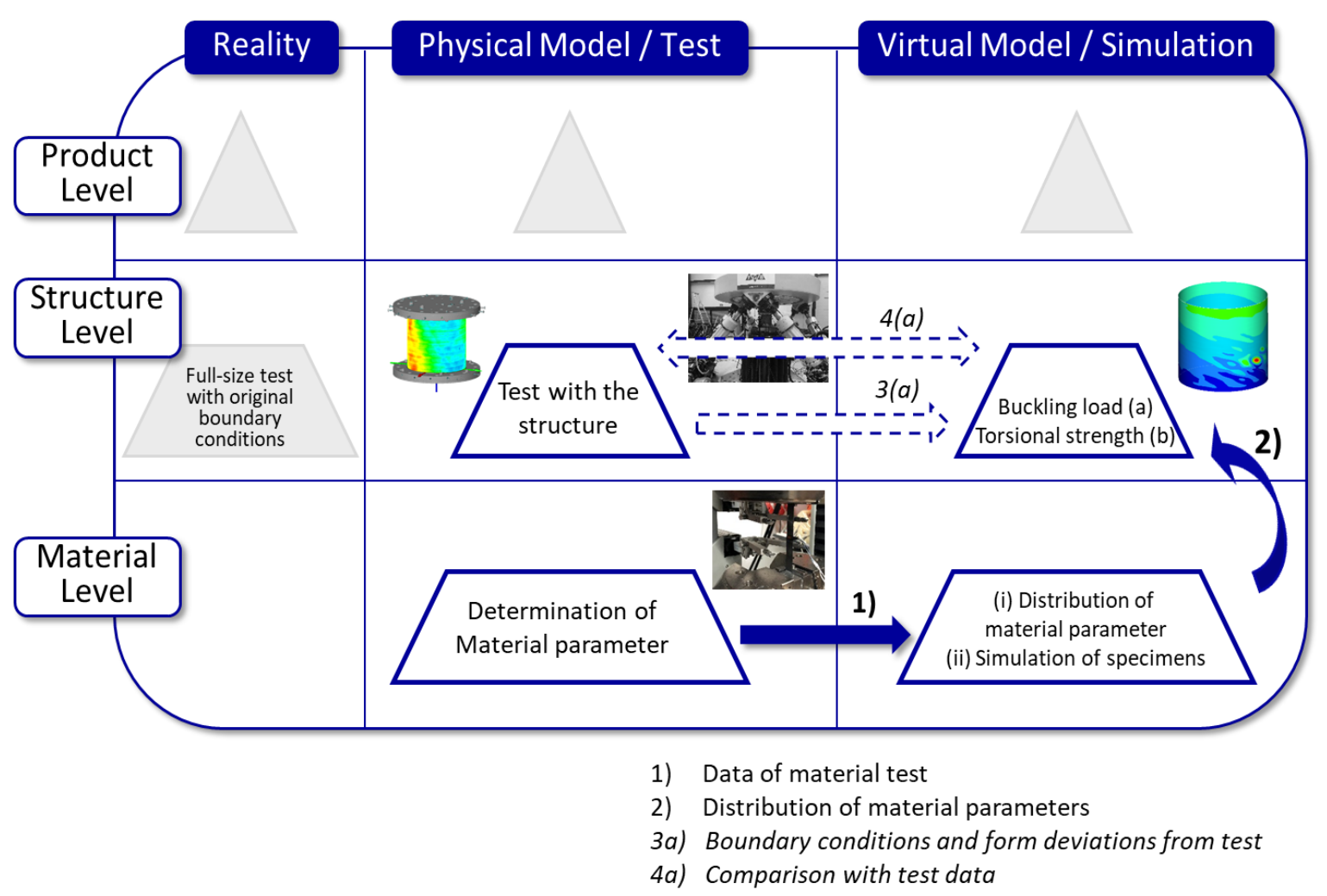

Figure 2: Approach for the consideration of material and structural uncertainties in the design of lightweight structures 


\subsection{Analysis on the material level - Coupon specimens}

In a first step, coupon specimens with unidirectional and multidirectional lay-up are tested according to DIN EN ISO 527 [9]. The specimens were manufactured at DLR Braunschweig. The single layers of the laminate structure of the coupon specimens were placed on a winding core of slittapes. Afterwards, they were cut along the axis of the core and laid into a laminate manually. Finally, they were cured in an autoclave. As material AS7/8554 from Hexcel is chosen. In Figure 3 the tested coupon specimens are depicted. Ten specimens with unidirectional layup are tested. For the determination of the PoIsSON's ratio on five specimens in the middle of the specimen a strain gauge is placed perpendicular to the tension direction (see Figure 4). In addition, two sets of five specimens each were tested with a multiaxial layup. The tests are carried out on a Zwick/Roell Z100 with extensiometer and a crosshead speed of $2 \mathrm{~mm} / \mathrm{min}$.
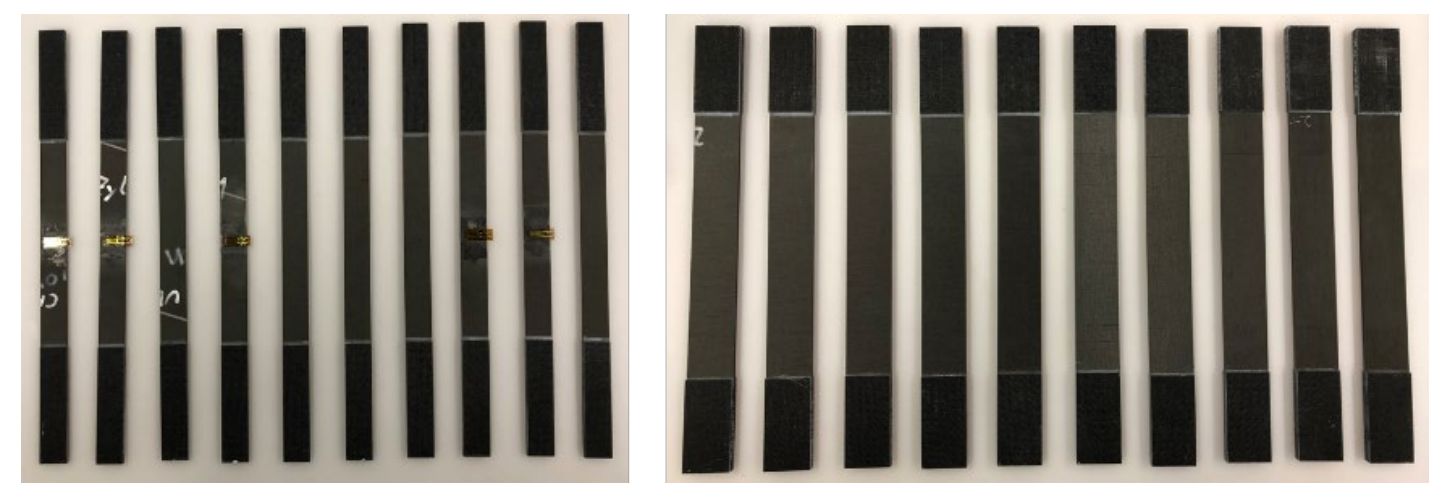

Figure 3: Tested Coupon Specimen

The Young's modulus and tensile strength of all specimens are quantified. Furthermore, the PoIsson's ratio for the unidirectional specimen is calculated. In Table 1 the results are shown. Since the distribution of the Young's modulus and the PoIsson's ratio of the unidirectional specimens are direct input parameters for Monte Carlo simulations on the structural level, their distribution is checked. A KOLMOGOROW-SMIRNOW test proves a normal distribution for both parameters. Furthermore, a determination of the covariance shows that the PoISSON's ratio and the Young's modulus are independent from each other.

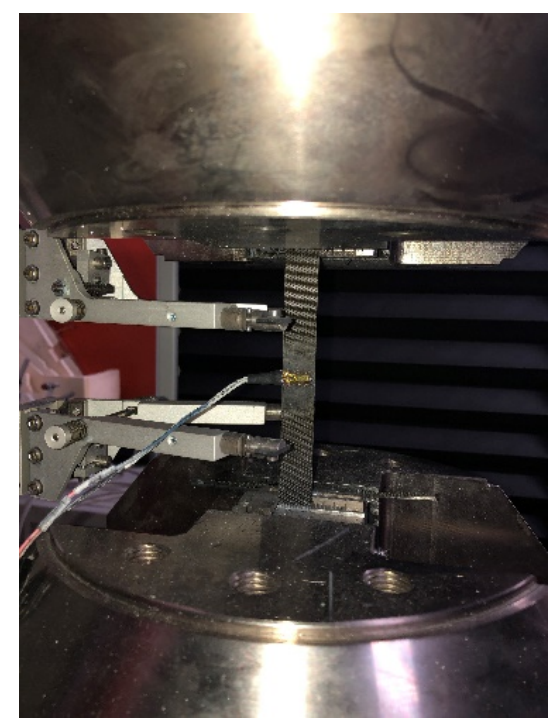

Figure 4: Test of a UD coupon specimen with strain gauge 
For better understanding of the material's behaviour and scattering of the parameters the coupon specimens are simulated in their lay-up after testing. Simulation of the coupon specimens was set up using ANSYS Composite PrepPost. Overall thickness of specimen being set to the mean of the measured specimen thickness, individual layers thicknesses were divided up equally from this value, resulting in total thickness of $1.12 \mathrm{~mm}$ for $[0]_{8}, 2.52 \mathrm{~mm}$ for both $\left[90^{\circ} / \pm 60^{\circ} / \pm 60^{\circ} / 90^{\circ}\right]_{3}$ and $\left[0^{\circ} / \pm 30^{\circ} / \pm 30^{\circ} / 0^{\circ}\right]_{3}$.

Table 1: Layup, sample size and results of the coupon test

\begin{tabular}{llccc} 
Lay-up & $\mathbf{n}$ & $\begin{array}{c}\text { Young's modulus } \\
{[\mathrm{GPa}]}\end{array}$ & $\begin{array}{c}\text { tensile strength } \\
{[\mathrm{MPa}]}\end{array}$ & $\boldsymbol{v}$ \\
\hline$\left[0^{\circ}\right]_{8}$ & 10 & $137,0 \pm 4,4$ & $221,4 \pm 8,6$ & $0,31 \pm 0,03^{1}$ \\
{$\left[90^{\circ} / \pm 60^{\circ} / \pm 60^{\circ} / 90^{\circ}\right]_{3}$} & 5 & $12,2 \pm 0,5$ & $11,8 \pm 0,1$ & - \\
{$\left[0^{\circ} \pm 30^{\circ} \pm 30^{\circ} / 0^{\circ}\right]_{3}$} & 5 & $77,7 \pm 1,4$ & $110,7 \pm 4,0$ & - \\
\hline
\end{tabular}

Young's modulus in x-direction $E_{1}$ and PoISSON's ratio $v_{12}$ were directly measured in the experiment. For the missing values of the orthotropic model, the material model uses values from [10] for $E_{2}$ and $E_{3}$ parameters. The remaining PoIsson's ratios were estimated to $\mathrm{v}_{13}=0.3$ and $v_{23}=0.4$; for shear moduli, also values obtained earlier in [10] were implemented, i. e. $G_{12}=$ $\mathrm{G}_{13}=3250 \mathrm{MPa}$ and $\mathrm{G}_{23}=2500 \mathrm{MPa}$. Figure 5 shows the simulation results using this material model and test specimen geometry from the experiment.

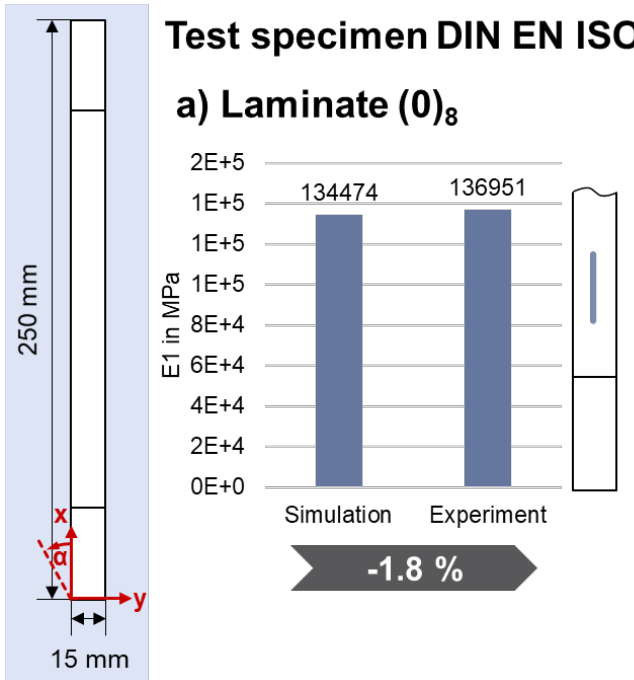

b) Lam. $\left[(90 /+60 /-60)_{\mathrm{s}}\right]_{3}$

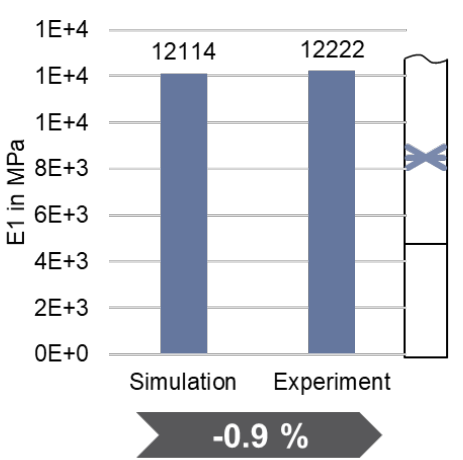

c) Lam. $\left[(0 /+30 /-30)_{\mathrm{s}}\right]_{3}$

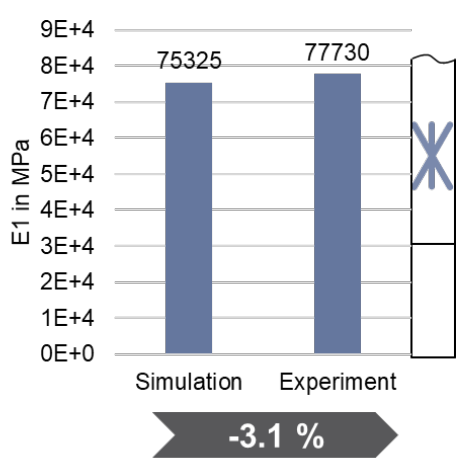

Figure 5: Comparison of experimental and simulation coupon test results: a) $[0]_{8}$; b) $\left[90^{\circ} / \pm 60^{\circ} / \pm 60^{\circ} / 90^{\circ}\right]_{3}$, c) $\left[0 \% \pm 30^{\circ} / \pm 30^{\circ} / 0^{\circ}\right]_{3}$ laminated coupon specimen.

Overall, simulation results are in good accordance with the experimentally determined results. Deviations are $-1.8 \%$ for $[0]_{8},-0.9 \%$ for $\left[90^{\circ} \% \pm 60^{\circ} / \pm 60^{\circ} / 90^{\circ}\right]_{3}$ and $-3.1 \%$ for the $\left[0^{\circ} / \pm 30^{\circ} \pm 30^{\circ} / 0^{\circ}\right]_{3}$ laminate.

\subsection{First transfer to the structure level - Torsional strength}

Considering this accordance between simulation and experiment, the material model is applied to a CFRP cylinder under torsion load as a first transfer to structural level. Real cylinders have been built and measured; the FE model can be used for simulating real experiments to be conducted later. Figure 3 shows the simulation including load case and boundary conditions.

\footnotetext{
${ }^{1}$ The sample size is five
} 
A FE model for scrutinizing torsion strength is set up like in Figure 6a: A cylinder of $250 \mathrm{~mm}$ height is modeled in CAD, including a free length of $215 \mathrm{~mm}$ and a measured diameter of $114.86 \mathrm{~mm}$ like in the real experiment to be conducted later. The lower ring is fixed, a torsion moment of $500 \mathrm{Nm}$ is applied virtually on the upper rim of the cylinder. Total wall thickness of the modeled $[90.5 /+30 /-30]_{\mathrm{s}}$ laminate is $0.8 \mathrm{~mm}$ as measured in the experimental specimen. The $90.5^{\circ}$ layer is not exactly $90^{\circ}$ as the real specimen is winded.
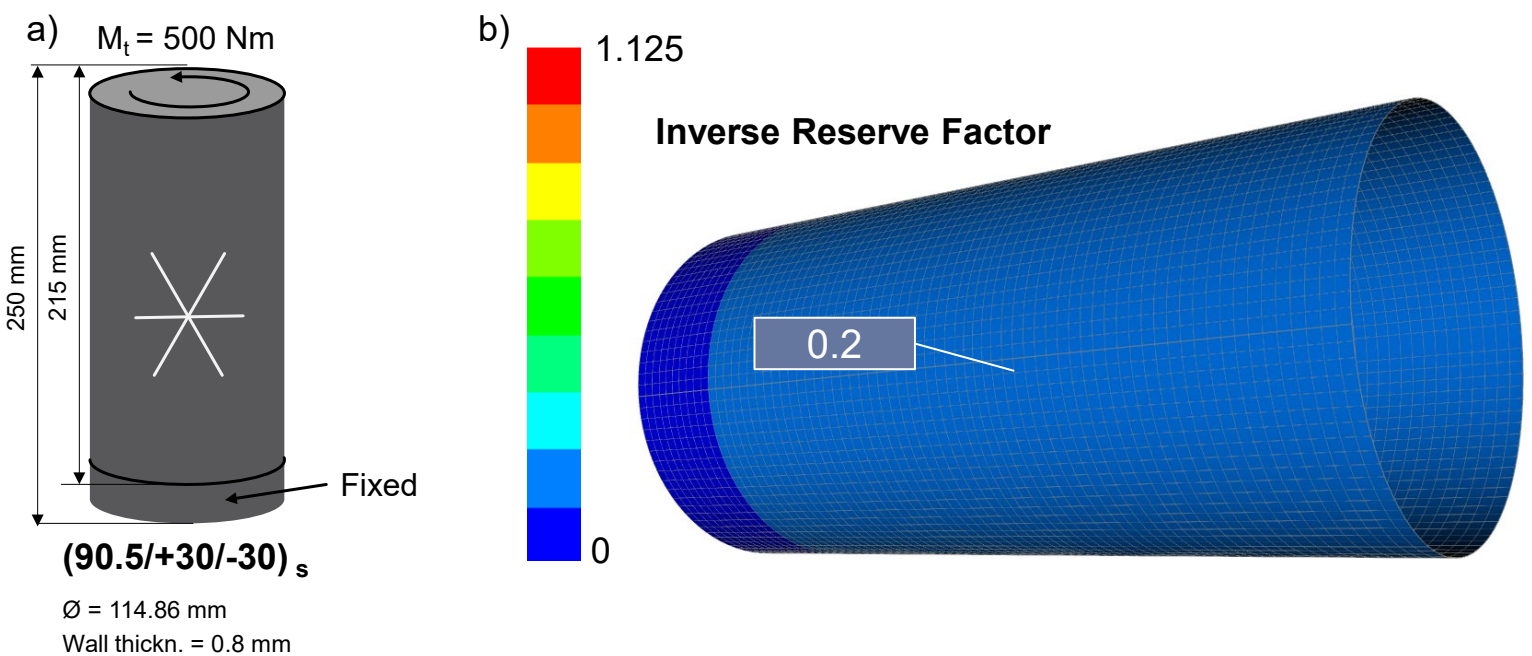

Figure 6: Torsional strength of CFRP cylinder: a) Settings for FE model, b) Inverse Reserve Factor.

Conducting an initial FE simulation, a simple TSAI-HILL failure criterion is implemented using standard orthotropic strength values from ANSYS database, supplemented by the mean tensile strength in fiber direction from the coupon tests of $2192.63 \mathrm{MPa}$. Figure $6 \mathrm{~b}$ then shows inverse reserve factors of 0.2 (reserve factor of 5 ) in the stressed region of the part. Later, this simulation can be compared to experiments; and strength values can be corrected, serving as a basis for product level within the building block approach.

\subsection{Second transfer to the structure level - Buckling load}

Based on the determined material parameters the buckling load for the thin-walled cylindrical shell from chapter 4.2 is calculated. Furthermore, for the geometric imperfections and the load imperfections values from literature are used from [5] and [8]. As shown in [10] the most relevant parameters for the buckling load are the Young's modulus in fibre direction, the geometric imperfections and load imperfections. For the load imperfections a KOLMOGOROW-SMIRNOW test proves normal distribution. Usually the geometrical imperfections are described by coefficents of a double Fourier series [11]. This is also done in this paper. Since in the cosine representation the values in the boundary areas need not be zero, this one is chosen. For the fourier coefficients a KOLMOGOROW-SMIRNOW test shows with a few exceptions normal distribution. For the sake of simplicity, a normal distribution is therefore also assumed for these.

In a numerical study, mean values are first assumed for all parameters and the corresponding buckling load is calculated. Subsequently, the individual influencing variables are successively considered as scattering parameters. In addition to these considerations, a combination of a lower bound and mean values for the material parameters and the load imperfections are also investigated. The buckling loads are calculated for all FE-models in a nonlinear, load-controlled analysis in ABAQUS/implicit with a mesh density of 214 axial and 722 radial nodes. Thus, the elements have an edge length of $1 \mathrm{~mm}$ and a convergence study 
from [8] shows the suitability of this size. The geometry is modeled with S4R shell elements, and the force introduction and support are realized by a master node rigidly coupled to the upper and lower side.

In Table 2 the results of the different approaches are shown. For the three probabilistic approaches, 200 artificial cylinders were generated for each study and their buckling load was calculated. Figure 7 shows the cumulative distribution function of the three studies. As buckling load 0.01 quantile value is used. With a number of samples of 200 this results in an accuracy of $2.8 \%$. The highest buckling load is calculated by using the mean values of the material parameters, the geometric imperfections and the lateral forces. If the material uncertainties, the distribution of the form deviations and the lateral forces are successively taken into account, the calculated buckling load decreases with each considered uncertainty. However, the consideration of the material uncertainties reduces the buckling load at most.

Table 2: Different model parameter and calculated Buckling load of the CFRP cylinder shell

\begin{tabular}{llll}
\hline Materialparameter & $\begin{array}{l}\text { Geometric } \\
\text { Imperfections }\end{array}$ & Load Imperfections & Buckling Load \\
\hline Average values & Average values & Average values & $70,65 \mathrm{kN}$ \\
Lower bound & Average values & Average values & $66,71 \mathrm{kN}$ \\
Lower bound & Average values & Lower bound & $63,62 \mathrm{kN}$ \\
Monte Carlo & Average values & Average values & $65,99 \mathrm{kN}$ \\
Monte Carlo & Monte Carlo & Average values & $65,62 \mathrm{kN}$ \\
Monte Carlo & Monte Carlo & Monte Carlo & $63,61 \mathrm{kN}$ \\
\hline
\end{tabular}

Whereas, the use of the lower bound values of the material parameters leads to comparable design load as the probabilistic approach. If the worst case of all lateral forces is also used, even the lowest buckling load is calculated. However, lateral forces in this form have not occurred in the tests.

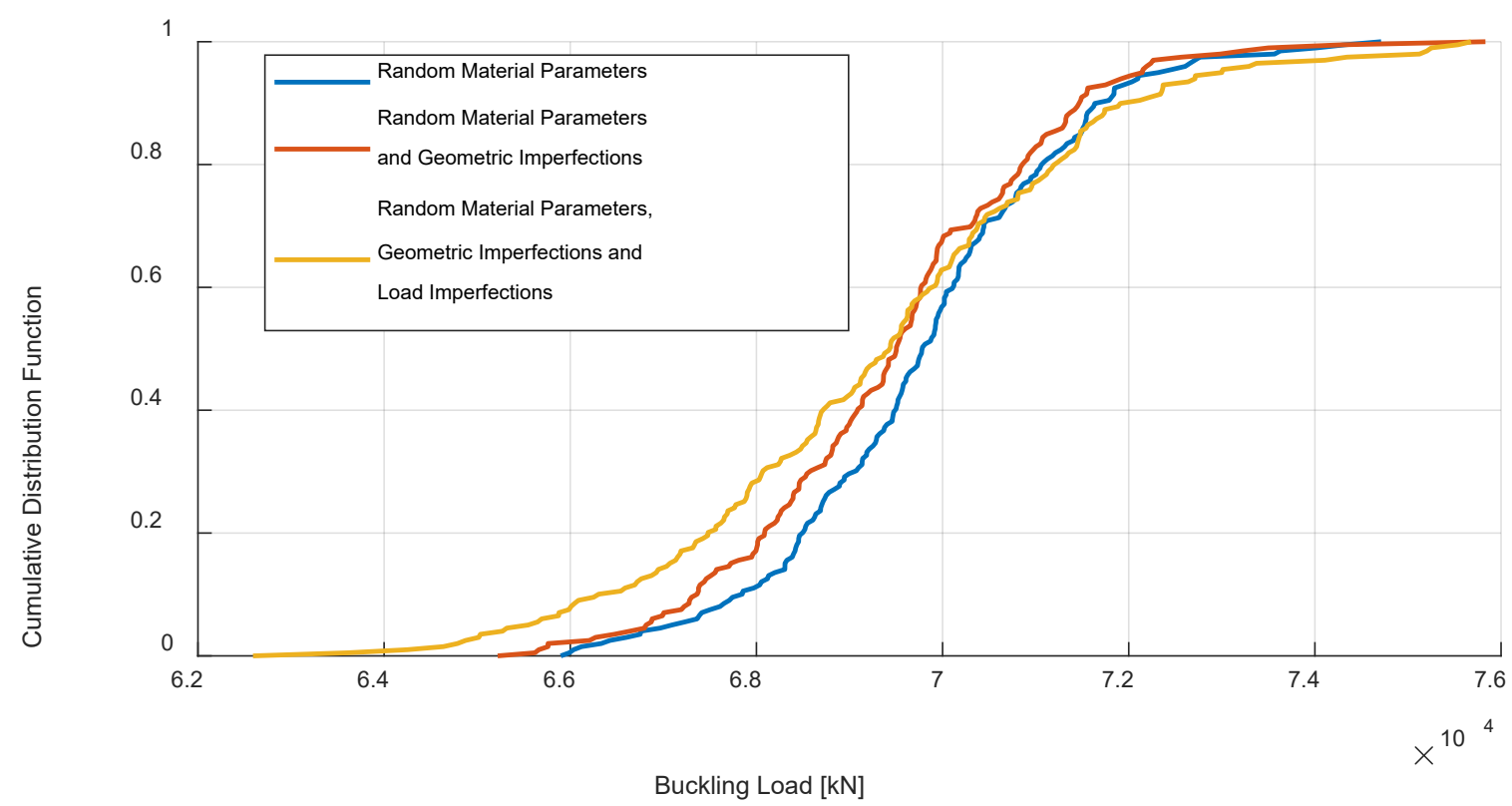

Figure 7: Cumulative Distribution Function of the buckling load of three different detailed calculations

Finally, the simulation results are compared with a test result. In [12] a comparable cylinder has been tested. A buckling load of $59.90 \mathrm{kN}$ was achieved with this cylinder. Thus, all approaches overestimate the buckling load. However, it should be noted here that the simulated buckling load of this cylinder with the material parameters determined in this paper 
and the geometric imperfections and transverse forces determined from [12] is $71.2 \mathrm{kN}$. This fact indicated that the material values were not to be adopted without adjustments. Further influencing factors such as the thickness distribution of the cylinder wall or existing internal stresses must also be taken into account.

Nevertheless, this example shows very well how uncertainties from the material level influence the results on the structural level. It is also shown how further uncertainties from the structure level can be taken into account in the design and how they influence the design.

\section{Conclusion and Outlook}

The consideration of uncertainties is of major importance in the design of lightweight structures, as these are optimized for specific load cases. If changes in the boundary conditions or even more than assumed scattering material parameters occur, the component may fail if the design is not robust. In this paper an approach for the consideration of uncertainties at different levels of the design was shown. It was demonstrated how experimental results including their uncertainties can be integrated into building up simulations and how missing values can be estimated simulatively.

In a next step, further influencing factors and their uncertainties must be considered, so that a better match between test and simulation result is achieved. Furthermore, the generalizability of this approach should be demonstrated. A good possibility would be to apply this approach to the fatigue design of fiber reinforced components as indicated in [13].

\section{Acknowlegdements}

This research was funded by the German Research Foundation (DFG) via the project "Zuverlässigkeitsbasierte Auslegung unversteifter CFK-Zylinderschalen unter Material- und Strukturunsicherheiten" (KR 3478-11-1). The statements and information in this contribution do not necessarily represent the opinion of DFG.

\section{References}

[1] Krause, Dieter et al.: Leichtbau. In: Rieg, Frank.; Steinhilper, Rolf (Hrsg.): Handbuch Konstruktion. München: Carl Hanser Verlag München, 2018, S. 487 - .507.

[2] Heyden, Emil et al.: Transferability of Boundary Conditions in Testing and Validation of Lightweight Structures. In: Krause, Dieter.; Paetzold, Kristin; Wartzack, Sandro. (Hrsg.): Design for X. Beiträge zum 30. DfX-Symposium, 2019.

[3] Haldar, Achintya.; Mahadevan, Sankaran.: Probability, reliability and statistical methods in engineering design, Wiley, New York, NY, 2000.

[4] Department of Defense (Hrsg.): Composite Materials Handbook. Volume 3. Polymer Matrix Composites Materials Usage, Design, and Analysis, Washington, 2002.

[5] Schillo, Conny.: Reliability based design of unstiffened fibre reinforced composite cylinders. Dissertation, Technische Universität Hamburg-Harburg, 2016.

[6] Handbuch Eurocode 0 - Grundlagen der Tragwerksplanung. Vom DIN konsolidierte Fassung. Bauwesen, Beuth, Berlin, 2011.

[7] Chamis, C. C.: Probabilistic simulation of multi-scale composite behavior. In: Theoretical and Applied Fracture Mechanics 41, 2004, 1-3, S. 51-61.

[8] Schillo, C.; Röstermundt, D.; Krause, D.: Experimental and numerical study on the influence of imperfections on the buckling load of unstiffened CFRP shells. In: Composite Structures 131 , 2015, S. 128-138.

[9] DIN EN ISO 527-1:2019-12, Kunststoffe- Bestimmung der Zugeigenschaften- Teil_1: Allgemeine Grundsätze (ISO_527-1:2019); Deutsche Fassung EN_ISO_527-1, 2019.

[10] Schillo, Conny.; Kriegesmann, Benedikt.; Krause, Dieter: Reliability based calibration of safety factors for unstiffened cylindrical composite shells. In: Composite Structures 168, 2017, S. 798-812.

[11] Arbocz, Johann.; Starnes Jr, James H.: Future directions and challenges in shell stability analysis. In: ThinWalled Structures 40 2002, Nr. 9, S. 729-754. 
[12] Hartwich, Tobias S.; Krause, Dieter: The Influence of Geometric Imperfections of Different Tolerance Levels on the Buckling Load of Unstiffened CFRP cylindirical shells. In: 22th International Conference on Composite Materials (ICCM22), Melbourne, 2019, 4502-4511., 2019.

[13] Hartwich, Tobias. S. et al.: Zur Notwendigkeit eines konstruktionsmethodischen Ansatzes für die zeitfeste Auslegung endlosfaserverstärkter Kunststoffbauteile. In: Krause, Dieter.; Paetzold, Kristin; Wartzack, Sandro. (Hrsg.): Design for X. Beiträge zum 30. DfX-Symposium, 2019. 